\title{
A Novel COL4A1 Mutation in a Neonate with Intrauterine Intraventricular Hemorrhage and Porencephaly
}

Jihyun Noh, MD ${ }^{1}$ Euiseok Jung, MD , Ah Young Jung, $\mathrm{MD}^{2}$, Beom Hee Lee, MD, $\mathrm{PhD}^{1}$, Byong Sop Lee, MD, $\mathrm{PhD}^{1}$, Ellen Ai-Rhan Kim, MD, $\mathrm{PhD}^{1}$, and Ki-Soo Kim, $\mathrm{MD}, \mathrm{PhD}^{1}$

Departments of ${ }^{1}$ Pediatrics and ${ }^{2}$ Radiology, Asan Medical Center, University of Ulsan College of Medicine, Seoul, Korea

\section{ABSTRACT}

Collagen type IV alpha 1 (COL4A1) plays an important role in construction of the basement membranes of all human tissues, especially vessels. Mutations in COL4A1 lead to various multisystemic dysfunctions, including hereditary porencephaly, hemorrhagic stroke, hemiplegia, cerebral small vessel disease, and nephropathy. In this study, we describe a neonatal case featuring a novel de novo COLAA1 mutation, manifesting as fetal intraventricular hemorrhage and porencephaly. This patient is one of the youngest to have been diagnosed with the most severe phenotype. Our experience may assist clinicians in the diagnosis and management of this extremely rare genetic condition.

Key Words: Cerebrovascular disorders; Collagen; Genetics; Hemorrhage; Stroke

\section{INTRODUCTION}

Fetal porencephaly is classified into two subtypes: developmental and encephaloclastic. The former represents the primary failure of neuronal development and migration, and the latter develops when an environmental or genetic insult destroys a normally developed brain. Congenital encephaloclastic porencephaly has many different causes; of these, a defect in collagen type IV alpha 1 (COL4A1) leads to fragile blood vessels with fetal hemorrhagic strokes $^{1)}$. COL4A1 is located on chromosome $13 \mathrm{q} 34$, and encodes the COL4A1 ${ }^{2)}$. COL4A1, which is expressed in all tissues, is a crucial component of basement membrane proteins. In particular, it is an integral protein in angiogenesis, regulating blood vessel tone, cohesiveness of the basal membrane, and endothelial function ${ }^{3)}$. Defects in COL4A1 lead to multisystemic abnormalities affecting the brain, eyes, kidneys, muscle, and other organs ${ }^{4,5)}$. In particular, the affected fetus may present with intrauterine intraventricular hemorrhage and subsequent porencephaly or schizencephaly.

In this report, we describe a male newborn affected by severe fetal porencephaly and a heterozygous mutation. To the best of our knowledge, this is the youngest child with a reported $C O L 4 A 1$ defect.
Received: 27 June 2019

Revised: 17 September 2019

Accepted: 7 October 2019

Correspondence to: Euiseok Jung, MD

Department of Pediatrics, Asan Medical Center, University of Ulsan College of Medicine, 88 Olympic-ro 43-gil, Songpa -gu, Seoul 05505, Korea

Tel: +82-2-3010-3372

Fax: +82-2-3010-7302

E-mail: euisjung@amc.seoul.kr

Copyright(c)

By Korean Society of Neonatology.

All right reserved.

This is an Open-Access article distributed under the terms of the Creative Commons Attribution Non-Commercial License (http:// creativecommons.org/licenses/by-nc/4.0), which permits unrestricted non-commercial use, distribution, and reproduction in any medium, provided the original work is properly cited. 


\section{CASE REPORT}

A male newborn was born vaginally at $38+3$ weeks' gestation to a 31-year-old mother. At 21 weeks' gestation, he was suspected to have intraventricular hemorrhage, porencephaly, and bilateral cataracts, identified during prenatal ultrasonography (Figure 1). There was no family history of congenital anomaly and systemic illness including his parents and two healthy brothers.

His birth weight, birth length, and head circumference were $2,180 \mathrm{~g}(<3$ rd percentile), $45 \mathrm{~cm}$ ( $<3$ rd percentile), and $31 \mathrm{~cm}(<3 \mathrm{rd}$ percentile), respectively. He had intrauterine growth retardation, but there were no complications during pregnancy. At birth, his Apgar scores were 7 and 9 at 1 and 5 minutes, respectively. On physical examination, microcephaly, micrognathia, facial purpura, and bilateral clubfoot were noted. On ophthalmological investigation, bilateral cataracts were found (Figure 2). His hemo globin level was $12.2 \mathrm{~g} / \mathrm{dL}$ and normocytic normochromic anemia without fragmented red blood cells (RBCs) were identified on a peripheral blood smear. His platelet count, prothrombin time, and activated partial thromboplastin time were normal. Tests for toxoplasmosis, rubella, cytomegalovirus infection, and herpes infection were all negative. Brain sonography at day 1 revealed proportionally dilated bilateral lateral ventricles that were more dilated anteriorly (Figure 3A). Brain magnetic resonance imaging at day 1 revealed bilateral ventriculomegaly communicating with extensive porencephaly in the bilateral frontal region (Figure 3B). There was marked cortical thinning with almost no discernible cortical mantle in the frontal region. In addition, evidence of previous hemorrhage with hemosiderin deposition along the margins of the ventricles and bilateral choroid plexi was noted

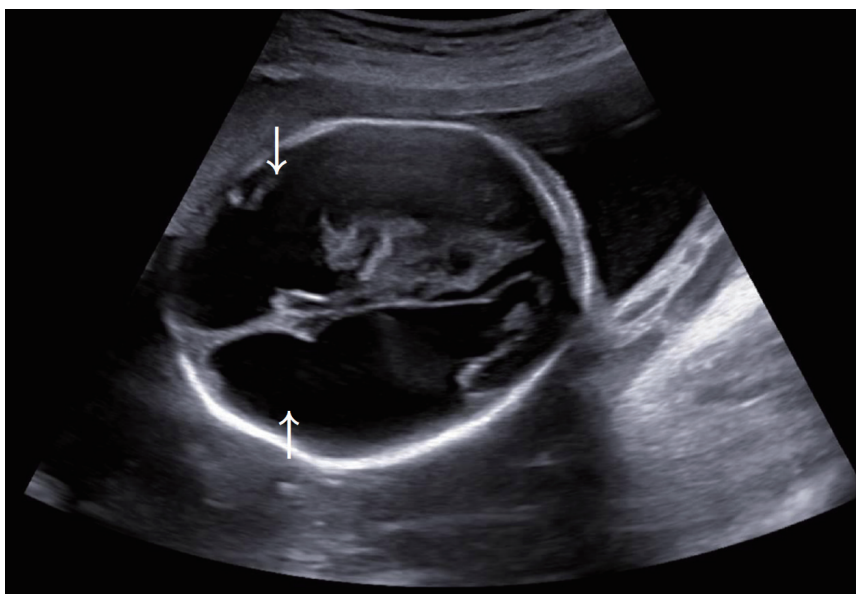

Figure 1. Bilateral frontal porencephaly on fetal sonography at 21 weeks of gestation (white arrows)
(Figure 3C). Magnetic resonance angiography revealed slightly attenuated intracranial vessels without significant tortuosity or abnormal dilatation. The results of electrocardiogram, echocardiogram, and kidney ultrasonography were normal. His karyo type was 46 , XY. The hospital course was uneventful, and he was discharged at 10 days of life (DOL).

At 2 months of age, he was admitted to our hospital because of an enterovirus infection. Hemolytic anemia, as indicated by a hemoglobin level of $6.3 \mathrm{~g} / \mathrm{dL}$ with fragmented RBCs, was noted. In addition, his reticulocyte, haptoglobin, and plasma hemoglo bin levels were $15.78 \%$, $<7.8 \mathrm{mg} / \mathrm{dL}$, and $8.9 \mathrm{mg} / \mathrm{dL}$, respectively. Direct and indirect Coombs test were negative. There was no definite evidence of additional hemorrhage on the brain ultrasonography at admission. He received a $10 \mathrm{~mL} / \mathrm{kg} \mathrm{RBC}$ transfusion, and his hemoglobin level at discharge was $7.6 \mathrm{~g} / \mathrm{dL}$. No additional transfusion was performed.

Partial exome sequencing of 4,813 Online Mendelian Inheritance in Man (OMIM) genes was performed using peripheral leukocytes at $10 \mathrm{DOL}$ under the suspicion of $C O L 4 A 1$ mutation. Exomes were captured using the TruSight One Panel (Illumina Inc., San Diego, CA, USA), which enriches a $12 \mathrm{Mb}$ region spann ing 4,813 genes. Sequencing was performed using the Next Seq platform (Illumina Inc.). Sequence reads were aligned to the reference genome, hg19, using BWA (v.0.7.12, MEM algorithm). The mean depth of coverage was $90 \times(>10 \times=98 \%)$. The hetero

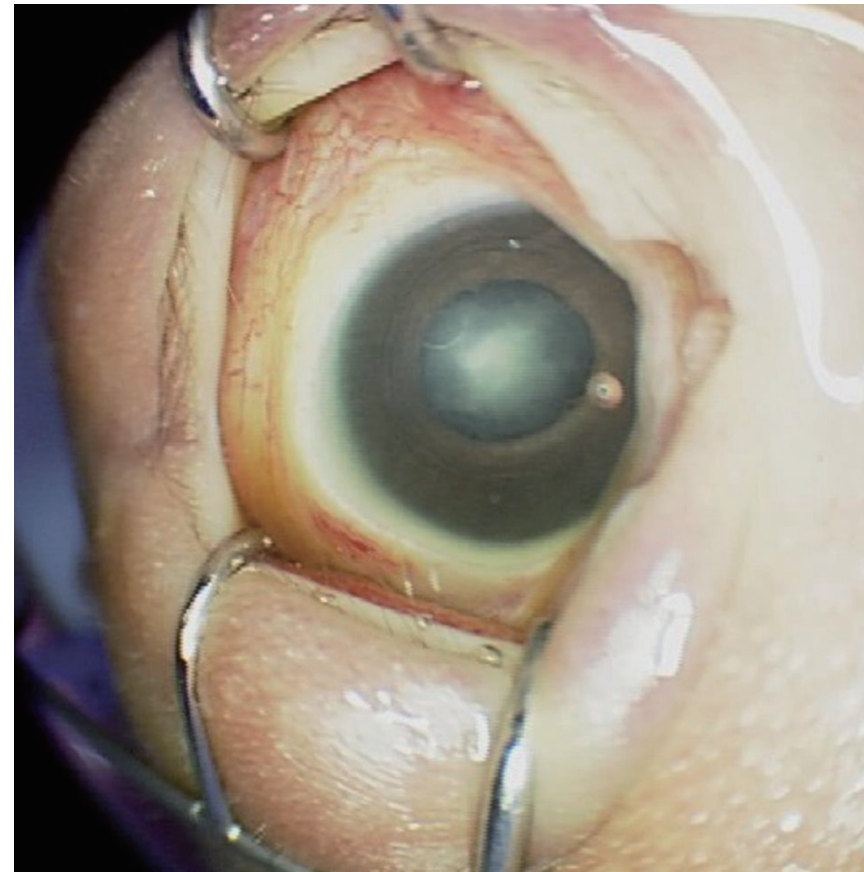

Figure 2. Right cataract of the patient. 

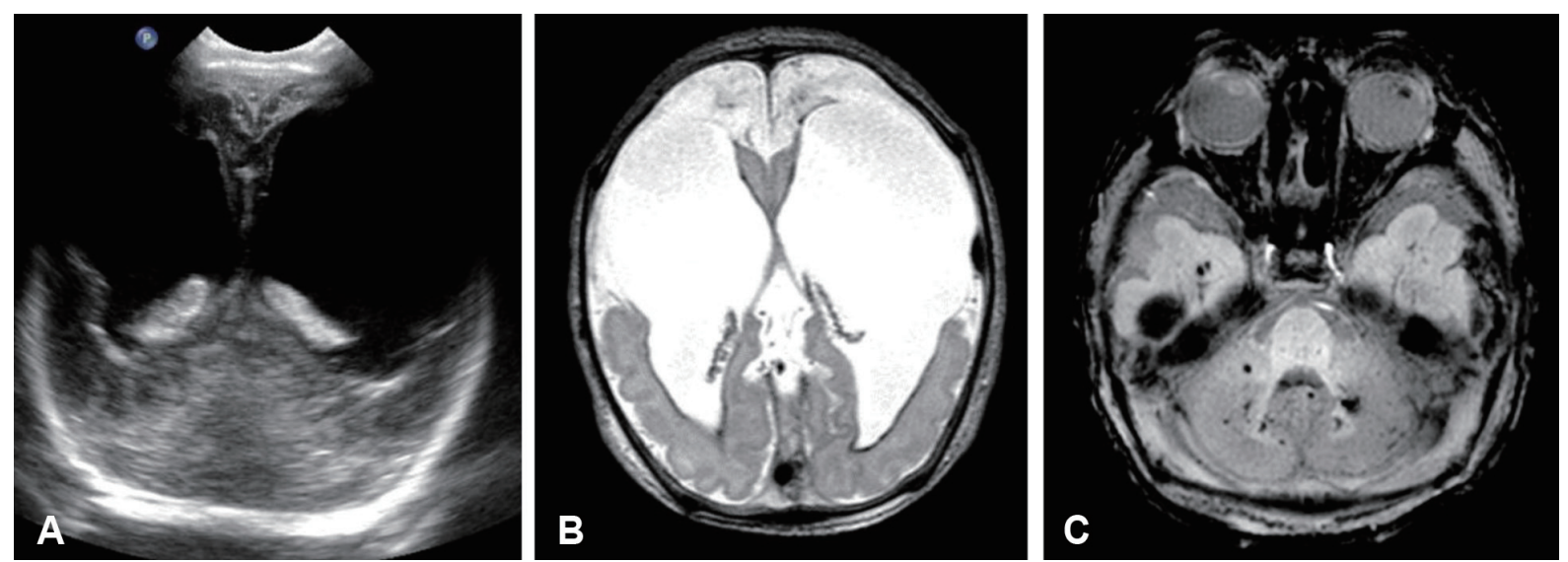

Figure 3. Images of a microcephalic newborn boy with collagen type IV alpha 1 (COL4A1) mutation. (A) Cranial ultrasonography revealed dysmorphic enlarged lateral ventricles. (B) Axial T2-weighted imaging of the brain revealed bilateral dilated lateral ventricles communicating with extensive frontal porencephaly. Marked thinning of the cortical mantle was noted in the bilateral frontal region. T2 dark signal intensity suggesting hemosiderin deposition was observed along the linings of the lateral ventricles. (C) Axial susceptibility weighted imaging revealed multiple foci of susceptibility in the cerebellum suggesting microhemorrhages.

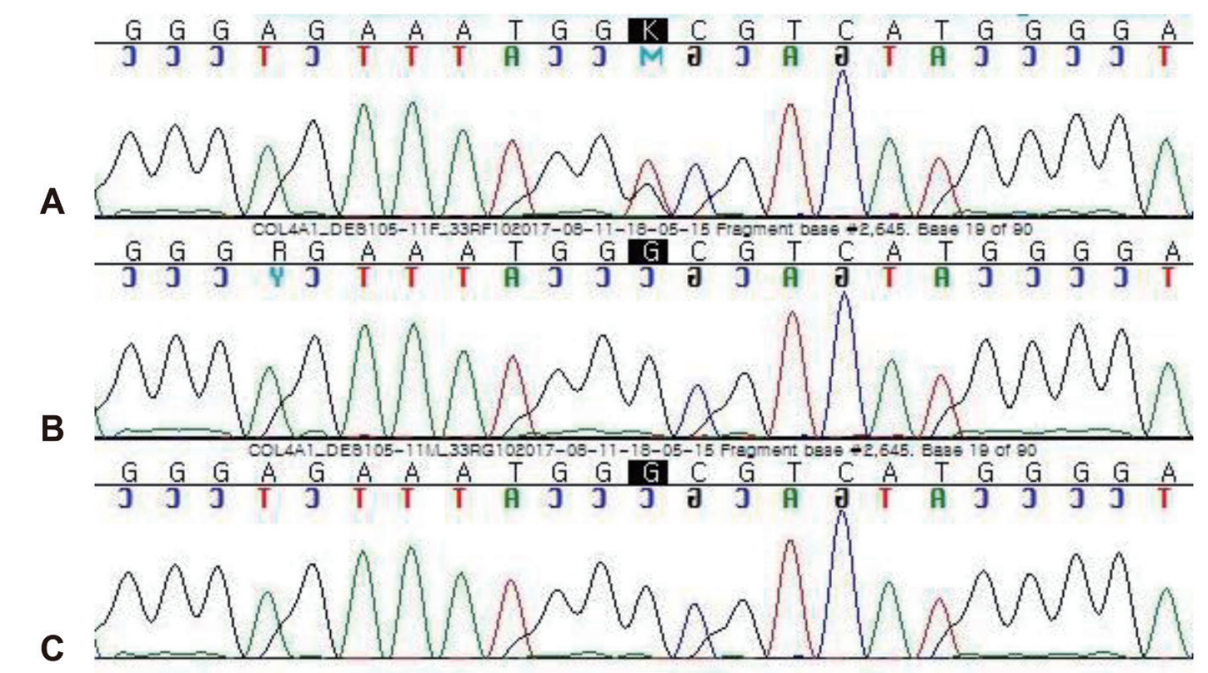

Figure 4. Sequence chromatograms revealed that a single heterozygous nucleotide change, c.2645G $>$ T (p.Gly882Val), was present (A) in the patient, but not in his (B) father or (C) mother.

zygous novel COL4A1 mutation c.2645G>T (p.Gly882Val) was identified (Figure 4). In silico prediction tools, PolyPhen-2 (http:// genetics.bwh.harvard.edu/pph2) and SIFT (http://sift.jcvi.org), were employed. This variant was classified as pathogenic according to the American College of Medical Genetics and Genomics ${ }^{6)}$. Neither of his parents carried the mutation.

At 9 months of age, phacoemulsification cataract extraction with posterior chamber lens implantation was performed for bilateral congenital cataracts. At 12 months of age, his weight, height, and head circumference were 10th percentile, 10th percentile, and under the 3rd percentile, respectively. He exhibited profound developmental delay. He could only roll supine to a prone position and make vowel-like noises. He was able to eat formula milk orally without a feeding tube, although intermittent aspiration occurred. On the Bayley Scale of Infant Development-II, his mental and psychomotor development indices were 8 and 15, respectively, indicating severe developmental cognitive and motor delay. $\mathrm{He}$ was diagnosed with epilepsy and took anticonvulsants. Hemolytic anemia was no longer observed after enterovirus infection. Microscopic hematuria was observed but no specific findings were found during renal sonography. 


\section{DISCUSSION}

As a component of type IV collagen, COL4A1 encodes its alpha 1 chain. This chain combines with another alpha 1 chain and the alpha 2 chain to form complete type IV collagen alpha 1-1-2 heterotrimers. These molecules attach to each other to form a complex protein network, which is important for basement mem brane interactions and cell migration, proliferation, maturation, and survival.

The spectrum of $C O L A A 1$ defect-related disorders includes cerebral small-vessel disease, variably associated eye defects(AxenfeldRieger anomaly, cataract, retinal arterial tortuosity, retinal anterior segment dysgenesis), and systemic disorders (kidney involvement, muscle cramps, Raynaud phenomenon, cardiac arrhythmia, and hemolytic anemia) ${ }^{7,8)}$. HANAC (hereditary angiopathy with ne phropathy, aneurysms, and muscle cramps) syndrome is usually associated with asymptomatic cerebral small vessel disease ${ }^{9,10)}$.

COL4A1 mutations represent an autosomal dominant cause of hereditary porencephaly, most often caused by germinal matrix hemorrhage leading to deep venous infarction with subsequent tissue necrosis and porencephalic cavitation ${ }^{1,10)}$. The incidence of $C O L 4 A 1$ mutations among 61 pediatric patients with porence phaly and schizencephaly was $21 \%$ in an analysis conducted by Yoneda et al. ${ }^{5)}$ In another cohort, 183 patients with porencephaly or infantile hemorrhage were selected, and the researchers identified 21 COL $4 A 1$ and 3 COL4A2 pathogenic mutations $(13 \%)^{4)}$.

In our case, the patient exhibited porencephaly, congenital cataract, and hemolytic anemia, which are the symptoms of COLAA1related disorders. Porencephaly, a typical manifestation of $C O L A A 1$ mutation, is characterized by cystic cavities that communicate with ventricles and that are thought to arise from germinal matrix hemorrhage. Previous studies reported a potential link between congenital cataracts and COL4A1 mutation ${ }^{11,12)}$. COL4A1 expression was measured in human embryonic and adult lens capsules. The differentiation of mesenchymal cells in the cornea and the formation of an anterior chamber depend on signals controlled by transcription factors that are specifically expressed in mesenchymal cells and on inductive signals from the lens. Mutations in COLAA1 may disrupt some lenticular signaling in the direction of mesenchymal cells ${ }^{13,14)}$. The hemolytic anemia reported in a previous study was also observed in the present case; however, the exact cause has not yet been identified, and other studies suggested that this symptom is less relevant to COL4A1 mutation ${ }^{5,15)}$. The patient also exhibited developmental delay, resulting from characteristic porencephaly. The neurologic patterns associated with $C O L 4 A 1$ mutation comprise a typical severe presentation and a spectrum of less common phenotypes. The typical severe phenotype with porencephaly was defined by severe developmental delay, intellectual and behavioral difficulties, microcephaly, and motor abnormalities on neurologic examination. Even in the absence of any cerebrovascular hemorrhage, some patients with COLAA1 mutations display leukoencephalopathy, calcification, or cerebral microbleeding. These silent defects might cause physical disability and global developmental delay ${ }^{16)}$.

COL4A1 mutations are passed on as autosomal dominant mutations, and most cases have been sporadic. Therefore, the risk for parents to have another affected child is less than $1 \%$. How ever, because of the possibility of germline mosaicism, prenatal genetic testing for future pregnancy might be required ${ }^{17)}$.

To the best of our knowledge, our case, which was diagnosed at $57 \mathrm{DOL}$, is the earliest diagnosed $C O L 4 A 1$ mutation case on re cord. After diagnosis, we were able to provide more accurate infor mation and more systematic clinical follow-up and treatment. In this disease, avoiding additional head trauma and anticoagulant exposure may help to reduce the risk of additional intracranial hemorrhage with personalized treatment for individual symptoms 17). Therefore, after a rapid diagnosis, parental education was offered to reduce additional head trauma. It also provided an oppor tunity for prenatal genetic counseling related to the future preg. nancy. In newborns with multiple congenital anomalies such as porencephaly, cataracts, and hemolytic anemia, it is important to consider COLAA1 mutation and conduct early genetic testing. In addition, we suggest careful antenatal genetic testing for $C O L 4 A 1$ mutations in fetuses with intrauterine brain hemorrhage, porencephaly, or schizencephaly given the currently undefined related phenotype.

\section{ARTICLE INFORMATION}

\section{Ethical statement}

The Institutional Review Board (IRB) approval for the study was received in June 2019. Informed consent was waived by the board. Retrospective data collection was approved by the IRB of Asan Medical Center (IRB No. 2019-0745).

\section{Conflicts of interest}

No potential conflict of interest relevant to this article was 
reported.

\section{Author contributions}

Conception or design: E.J., B.H.L.

Acquisition, analysis, or interpretation of data: J.N., E.J., A.Y.J.,

B.H.L.

Drafting the work or revising: J.N., E.J., A.Y.J., B.H.L., B.S.L., E.A.R.K., K.S.K.

Final approval of the manuscript: J.N., E.J., A.Y.J., B.H.L., B.S.L., E.A.R.K., K.S.K.

\section{ORCID}

Jihyun Noh https://orcid.org/0000-0003-1541-2131

Euiseok Jung https://orcid.org/0000-0003-0693-5627

\section{Acknowledgments}

None

\section{REFERENCES}

1. Gould DB, Phalan FC, Breedveld GJ, van Mil SE, Smith RS, Schimenti JC, et al. Mutations in Col4al cause perinatal cerebral hemorrhage and porencephaly. Science 2005;308:1167-71.

2. Decio A, Tonduti D, Pichiecchio A, Vetro A, Ciccone R, Limongelli I, et al. A novel mutation in COL4Al gene: a possible cause of early postnatal cerebrovascular events. Am J Med Genet A 2015;167A:810-5.

3. Durrani-Kolarik S, Manickam K, Chen B. COLAAl mutation in a neonate with intrauterine stroke and anterior segment dysgenesis. Pediatr Neurol 2017;66:100-3.

4. Meuwissen ME, Halley DJ, Smit LS, Lequin MH, Cobben JM, de Coo R, et al. The expanding phenotype of COL4A1 and COL4A2 mutations: clinical data on 13 newly identified families and a review of the literature. Genet Med 2015;17:843-53.

5. Yoneda Y, Haginoya K, Kato M, Osaka H, Yokochi K, Arai H, et al. Phenotypic spectrum of COLAAl mutations: porencephaly to schizencephaly. Ann Neurol 2013;73:48-57.

6. Richards S, Aziz N, Bale S, Bick D, Das S, Gastier-Foster J, et al.
Standards and guidelines for the interpretation of sequence variants: a joint consensus recommendation of the American College of Medical Genetics and Genomics and the Association for Molecular Pathology Genet Med 2015;17:405-24.

7. Vahedi K, Alamowitch S. Clinical spectrum of type IV collagen (COL4A1) mutations: a novel genetic multisystem disease. Curr Opin Neurol 2011;24:63-8.

8. Adam MP, Ardinger HH, Pagon RA, Wallace SE. GeneReviews [Internet]. Seattle: University of Washington; 2016. Chapter, COL4A1-related disorders [cited 2020 Jan 22]. Available from: https://www.ncbi.nlm.nih.gov/books/NBK7046.

9. Plaisier E, Gribouval O, Alamowitch S, Mougenot B, Prost C, Verpont $\mathrm{MC}$, et al. COL4A1 mutations and hereditary angiopathy, nephropathy, aneurysms, and muscle cramps. N Engl J Med 2007;357:2687-95.

10. Takenouchi T, Ohyagi M, Torii C, Kosaki R, Takahashi T, Kosaki K. Porencephaly in a fetus and HANAC in her father: variable expression of COL4A1 mutation. Am J Med Genet A 2015;167A:156-8.

11. Van Agtmael T, Schlotzer-Schrehardt U, McKie L, Brownstein DG, Lee AW, Cross SH, et al. Dominant mutations of Col4al result in basement membrane defects which lead to anterior segment dysgenesis and glomerulopathy. Hum Mol Genet 2005;14:3161-8.

12. Sibon I, Coupry I, Menegon P, Bouchet JP, Gorry P, Burgelin I, et al. COL4A1 mutation in Axenfeld-Rieger anomaly with leukoencephalopathy and stroke. Ann Neurol 2007;62:177-84.

13. Kelley PB, Sado Y, Duncan MK. Collagen IV in the developing lens capsule. Matrix Biol 2002;21:415-23.

14. Coupry I, Sibon I, Mortemousque B, Rouanet F, Mine M, Goizet C. Ophthalmological features associated with COL4Al mutations. Arch Ophthalmol 2010;128:483-9.

15. Cavallin M, Mine M, Philbert M, Boddaert N, Lepage JM, Coste $\mathrm{T}$, et al. Further refinement of COL4A1 and COL4A2 related cortical malformations. Eur J Med Genet 2018;61:765-72.

16. Zagaglia S, Selch C, Nisevic JR, Mei D, Michalak Z, HernandezHernandez L, et al. Neurologic phenotypes associated with COL4A1/2 mutations: expanding the spectrum of disease. Neurology 2018;91:e2078-88.

17. Gould DB, Phalan FC, van Mil SE, Sundberg JP, Vahedi K, Massin P, et al. Role of COL4A1 in small-vessel disease and hemorrhagic stroke. N Engl J Med 2006;354:1489-96. 